\title{
Optimization of process lability in logistics systems
}

\author{
Tamás Hartványi, Csaba I. Hencz*
}

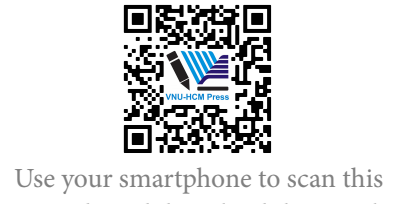

QR code and download this article
Széchenyi István University, Hungary

Correspondence

Csaba I. Hencz, Széchenyi István University, Hungary

Email: hencz@sze.hu

History

- Received: 06-5-2020

- Accepted: 28-10-2020

- Published: 13-11-2020

DOI : 10.32508/stdjet.v3iSI3.743

\section{Check for updates}

\section{Copyright}

(c) VNU-HCM Press. This is an openaccess article distributed under the terms of the Creative Commons Attribution 4.0 International license.

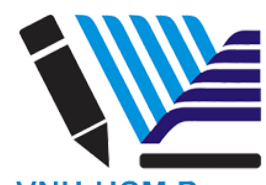

\begin{abstract}
The management and effective operation of enterprise systems - depending on ever-changing environmental impacts - can only be achieved by an appropriate information management practice. Today, in the corporate environment, an astonishing amount of data (often unstructured) is generated. The efficient processing of these data is by no means straightforward and unambiguous, and thus presents significant challenges for user systems. It is typical of the process that the customer would like to receive the product as soon as possible, but at least at a pre-determined time. Thus the quality of service is determined not only by the quality of the product but also by its availability. As is well known, the mission of logistics is to ensure the ordered product is delivered in the right time, place, quality, quantity and cost. In this mission has a specific product, finite duration, organizational structure with defined responsibilities, activities necessary for its production, and have the resources to carry out these activities. The processing of the product is divided into several stages, which form a separate unit from the managerial point of view. Like product procession, a section has specific products, activities, and organizational structure. The end of the phase is the production / implementation of the products / services specified therein, provided that they meet the required quality criteria. In our paper, we propose a methodology, which - together with the related mathematical model - can offer an opportunity to reduce entropy in logistics processes. The aim of the research is to develop a model that can be used to quantify the logistical process uncertainty. We believe that research will help find a way to overcome the shortcomings of current process management procedures. We give the formal description of the mathematical model and present an example of its application.
\end{abstract}

Key words: process liability, logistics systems, entropy

\section{INTRODUCTION}

In pull-based production management systems, planning for the production of an ordered product only begins after the order has been placed, so basically the race begins with time ${ }^{1}$.

It is typical of the process that the customer would like to receive the product as soon as possible, but at least at a pre-determined time. Thus the quality of service is determined not only by the quality of the product but also by its availability.

As is well known, the mission of logistics is to ensure the ordered product is delivered in the right time, place, quality, quantity and cost ${ }^{2}$.

In this mission has:

- a specific product,

- finite duration,

- organizational structure with defined responsibilities,

- activities necessary for its production,

- and have the resources to carry out these activities. The processing of the product is divided into several stages, which form a separate unit from the managerial point of view. Like product procession, a section has specific products, activities, and organizational structure. The end of the phase is the production / implementation of the products / services specified therein, provided that they meet the required quality criteria.

\section{AIM OF RESEARCH}

The aim of the research is to develop a model that can be used to quantify the logistical process uncertainty. We believe that research will help find a way to overcome the shortcomings of current process management procedures.

The basic idea of the research is the practical realization that after setting the goals the logistics organization often does not collect enough data in the socalled dead time (although in most cases there are no technical obstacles to data collection). But even when it is done, it is often impossible to deal with the fact that there are often harmful forms of information. All of this happens when the increasing complexity of IT systems brings with it ever greater risks in logistics $^{3}$.

The logistics organization usually has only one answer, which is in C. A. O'Reilly's hypothesis that 
higher-quality information sources are used more often by employees than lower-quality channels ${ }^{4}$.

\section{DESCRIPTION OF THE PROPOSED MODEL TO REDUCE PROCESS UNCERTAINTY}

In fact, the safety of the product manufacturing process is the planned use of tools and procedures to ensure that the customer's needs are met at the right time and level.

In other words, the uncertainty existing in the product manufacture should be reduced to acceptable levels by the client needs.

\section{Initial state}

Let's consider the initial state first! The uncertainty present at the beginning of the planning of the logistics process can be determined from historical data (depicted in Figure 1).

The horizontal axis shows the time from ordering to delivery of a particular product (denoted by tn). The vertical axis on the left shows the completion time expected by the customer (marked A). The right-hand side also shows the implementation time that is acceptable to the customer (denoted by $\varepsilon \mathrm{A}$ ).

The base axis of the vertical axes is represented by a constant time $c$, which may be 0 , which represents the theoretically imaginable minimum execution time of a given project (we cannot go below that during execution).

When using modern manufacturing and inventory management strategies, the deadline should be fixed. Therefore, companies should make every effort to deliver the product on time.

Improving the quality and flexibility of these processes is crucial for taking measures that focus on traditional efficiency ${ }^{5}$.

Several authors propose a heuristic approach to solve large, practical problems ${ }^{6,7}$.

Returning to our figure, the selected occurrence interval $(\varepsilon \mathrm{A})$ in our case is an expected optimum. Throughout the process, our goal is to guarantee that we are within the $\varepsilon$ A interval at the time of completion.

In the initial stages of the process, the time of completion can only be interpreted within a relatively large interval. Furthermore, there is a constant possibility of non-realization, which is indicated by an arrow (0) in the figure.

Ideally, logistics process planners in a point of $\mathrm{A}$ would need good and real information that they can use to develop their own production plan.
Typically, this data is not yet available in the first phase of design, this uncertainty is represented by the angle $\alpha$ and its projection on the right vertical axis $\varepsilon$ A.

In our proposed model, the uncertainty in the initial state can be considered acceptable, but we expect the uncertainty to decrease as the process progresses and remain within the $\varepsilon$ A environment.

\section{Milestones of the model}

After the initial state, we first check at time $t 1$. This can be seen as the first milestone of the model. At time $t 1$, the controllers, based on the information available to them, determine the new boundaries of the process run time, which is represented by the interval $\varepsilon \mathrm{B}$ in the figure. (This is also a kind of feedback on how the process works.)

Later, additional checkpoints may be added and similar analysis and feedback will be performed so that the data collected at each checkpoint is properly documented. This will (in good case) gradually predict the output more and more accurately. This is illustrated in the following Figure 3.

As shown in the Figure 4 (using well-designed practical control methods), ideally, $\delta<\gamma<\beta<\alpha$, which means that $\varepsilon \mathrm{D}<\varepsilon \mathrm{C}<\varepsilon \mathrm{B}<\varepsilon \mathrm{A}$, which means that accuracy is constantly increasing.

Increasing the number of checkpoints has a dual effect: on the one hand, it typically reduces uncertainty and thus better meets expected deadlines and reports; on the other hand, logistics costs may increase.

It is in the collective interest of those involved in the process to determine the optimal number of points. Later milestones may be overridden (if the project schedule changes).

In determining the number and location of control posts, account shall be taken of:

- the past goodness of information provided by the supplier. If this goodness is high, that is, the partner is trustworthy, there is no need for frequent checkpoints. - the spatial location of the product or service. If the location of production and use is different in space, the number of control points depends on the distance, so if the distance increases, the number of control points must be increased proportionally.

- the time of production of the product or service. If the production time is long, the number of control points should be high.

\section{LINKING MODELS}

Successful completion of a project does not necessarily mean completing the entire logistics process. Many times the output of one project is also the input of another project. 


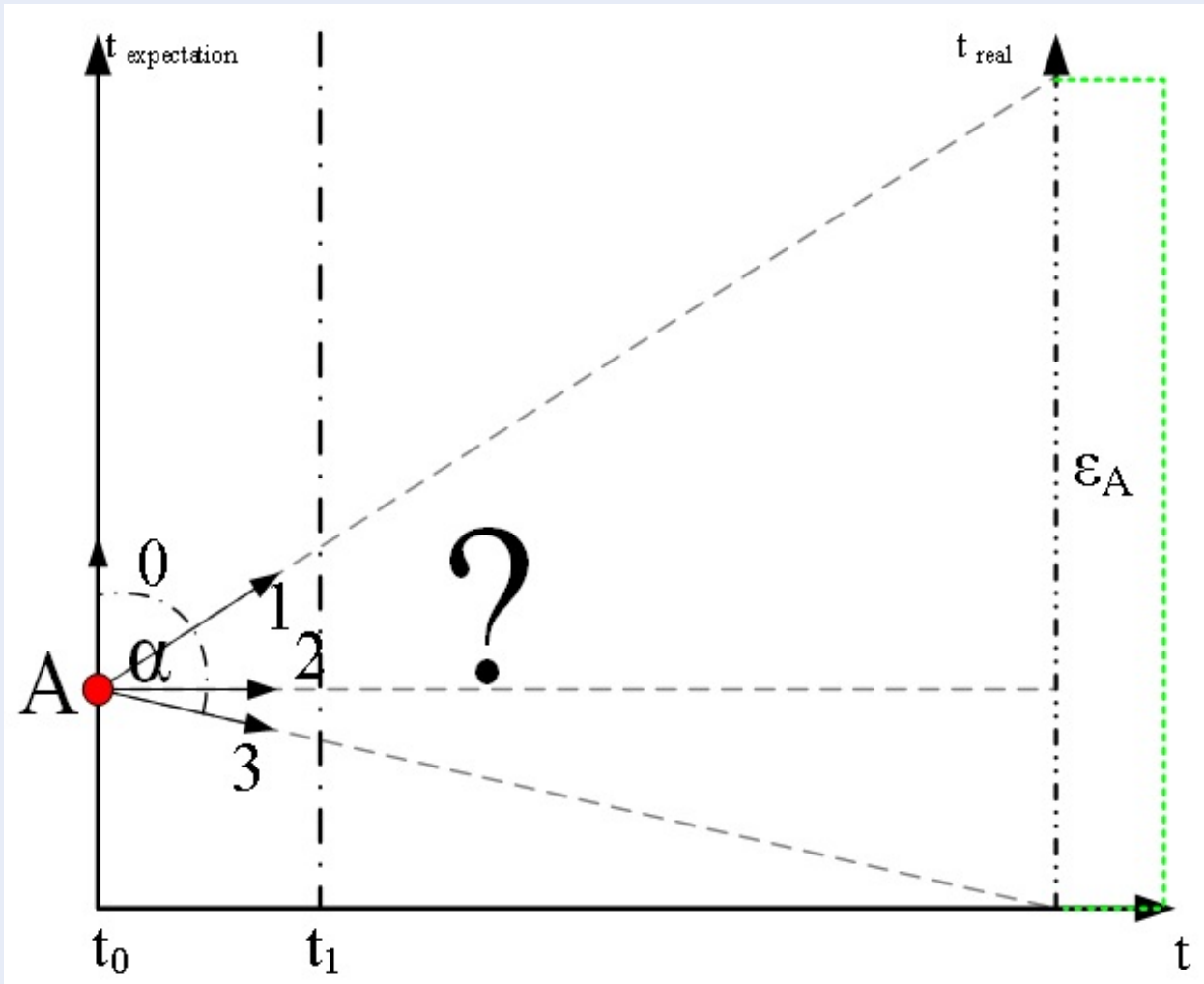

Figure 1: Uncertainty at the start of the project.

It is my hope that the methodology we have developed will allow us to describe and follow quite complex tasks.

\section{FORMAL DESCRIPTION OF THE MODEL AND DEMONSTRATION OF ITS APPLICABILITY}

Let's look at a possible formal description of the new model already outlined above.

Although the reality model could (in theory) end up in infinitely many different states, from a practical point of view, it is practical to use the simplification that only a finite number of states can go through the whole process.

Using C.E. Shannon's article ${ }^{8}$ - including his observations on the description of a noise-free channel (which can be regarded as a kind of analogy of our system) - our model can be formally described as follows:

The states of the system are denoted by state $S 1, S 2, \ldots$ $\mathrm{S} n$, where $\mathrm{n}$ is finite.

The occurrence probabilities of each state are denoted by $\mathrm{p} 1, \mathrm{p} 2, \ldots \mathrm{pn}$, where $0 \leq \mathrm{pi} \leq 1$ is satisfied for each value.
Transitional probabilities can be interpreted between states. Let pi(j) denote the probability of occurring $\mathrm{Si}$ $\rightarrow \mathrm{Sj}$ (going from $\mathrm{Si}$ to $\mathrm{Sj}$ ). (There will be many concrete pi $(j)=0$, because we can't always pass from $\mathrm{Si}$ to $\mathrm{Sj}$.)

Located in the Shannon model, the origin of our system can be considered as a source of discrete information, and the end point (s) of our system are special sinks.

Let's now look at the transition from baseline to first milestone! Usually we have several options (see Figure 1), but in good case, we have a 1 chance of reaching milestone 1. If we consider the failure of the project to be a viable alternative, we can write the following

$$
\sum_{i \in K, j \in E} p_{i(j)} \leq 1
$$

where $\mathrm{K}$ denotes the initial state (set of states) and $\mathrm{E}$ denotes the state of the first milestone. (The initial state set specifically consists of only one state.) It makes sense to write a similar formula for transitions between milestones.

The different probabilities of the occurrence of each $\mathrm{S} \_\mathrm{i} \rightarrow \mathrm{S} \_\mathrm{j}$ transition can be represented by arrows of 


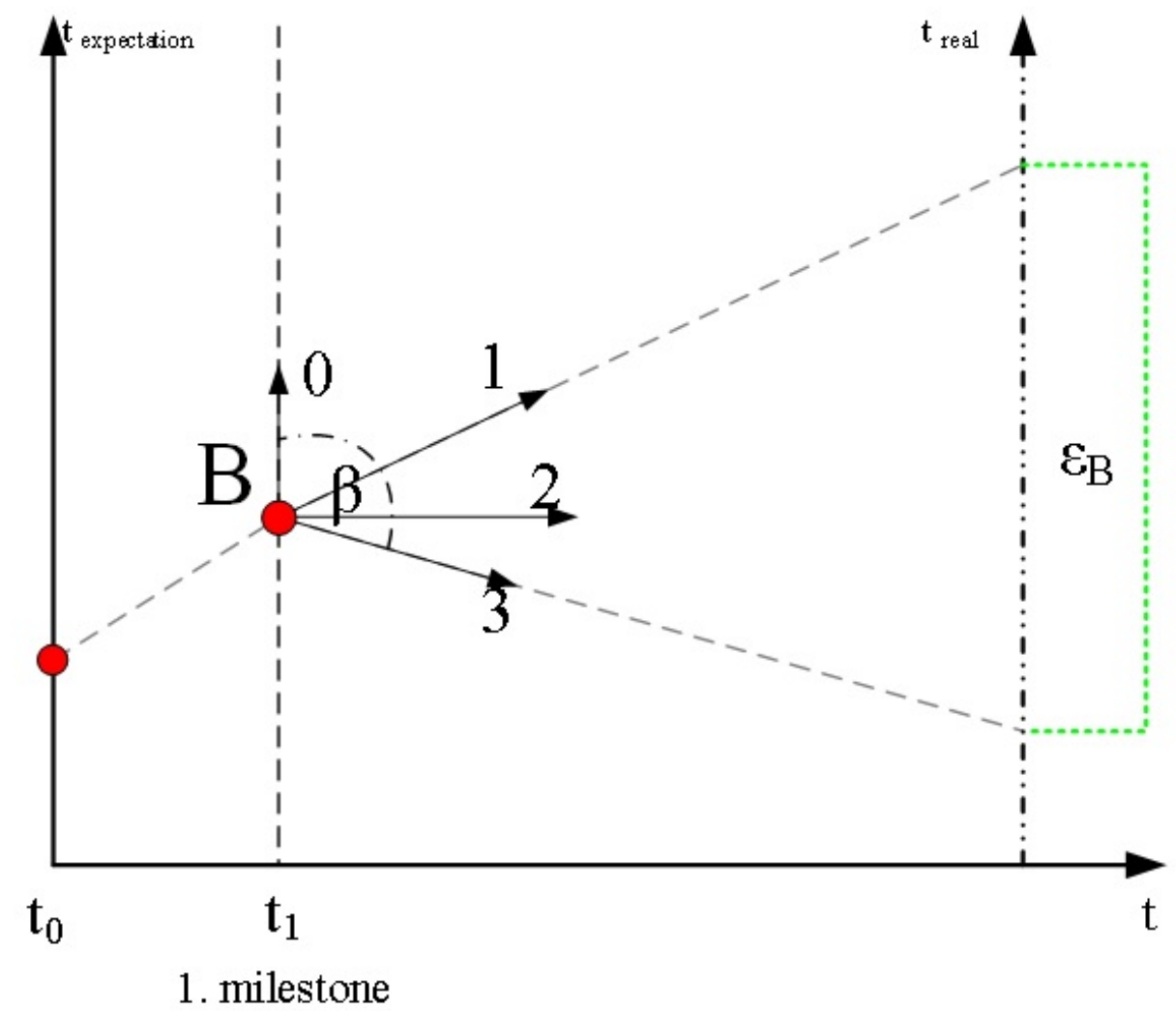

Figure 2: Logistics uncertainty at first milestone.

different thicknesses, but we can also write specific probabilities for each transition (see Figure 5).

We emphasize that possible states belong to the milestones. We determine in advance what kind of conditions we expect to see in each milestone based on professional experience (acquired knowledge, professional past, similar projects, etc.). The probability of possible states was determined from historical data. In the model, the horizontal arrow means that the process is progressing with a pre-planned schedule (keeping time). Delay is marked with a positive bearing (eg: $\nearrow$ ) faster execution is displayed with a negative bearing (eg \).

Note that the first milestone is theoretically available in several ways (meaning several different states in our model), only one of them will actually occur, so the probability of reaching the others (which were not originally 0 ) is set to 0 at this point. it! (And we're only going through exactly one "route".)

On arrival at the finish, there will be only one route active. Each transition actually carries 1 probability. We consider this to be a completed process.

\section{METHODOLOGY}

The practical applicability of our model requires that the repetition of a given situation brings with it a repetition of the model run. We can do this by making restrictions and specifying standards (standardization): - preliminary and in-process data collection,

- for recording / documentation,

- to process data

- and possible interventions.

The elements of this methodology are (of course) already known in logistics (Lörincz, 2009), but only in this way - with our model - can it still be said to be new.

The major steps we suggest (the items listed above) must be translated into specific workplace instructions. In this way, the process can be automated and standardized, and there is a legitimate hope that repeatability will be achieved.

\section{CONCLUSION}

During the research, we examined the shortcomings of current process control procedures. In response to 


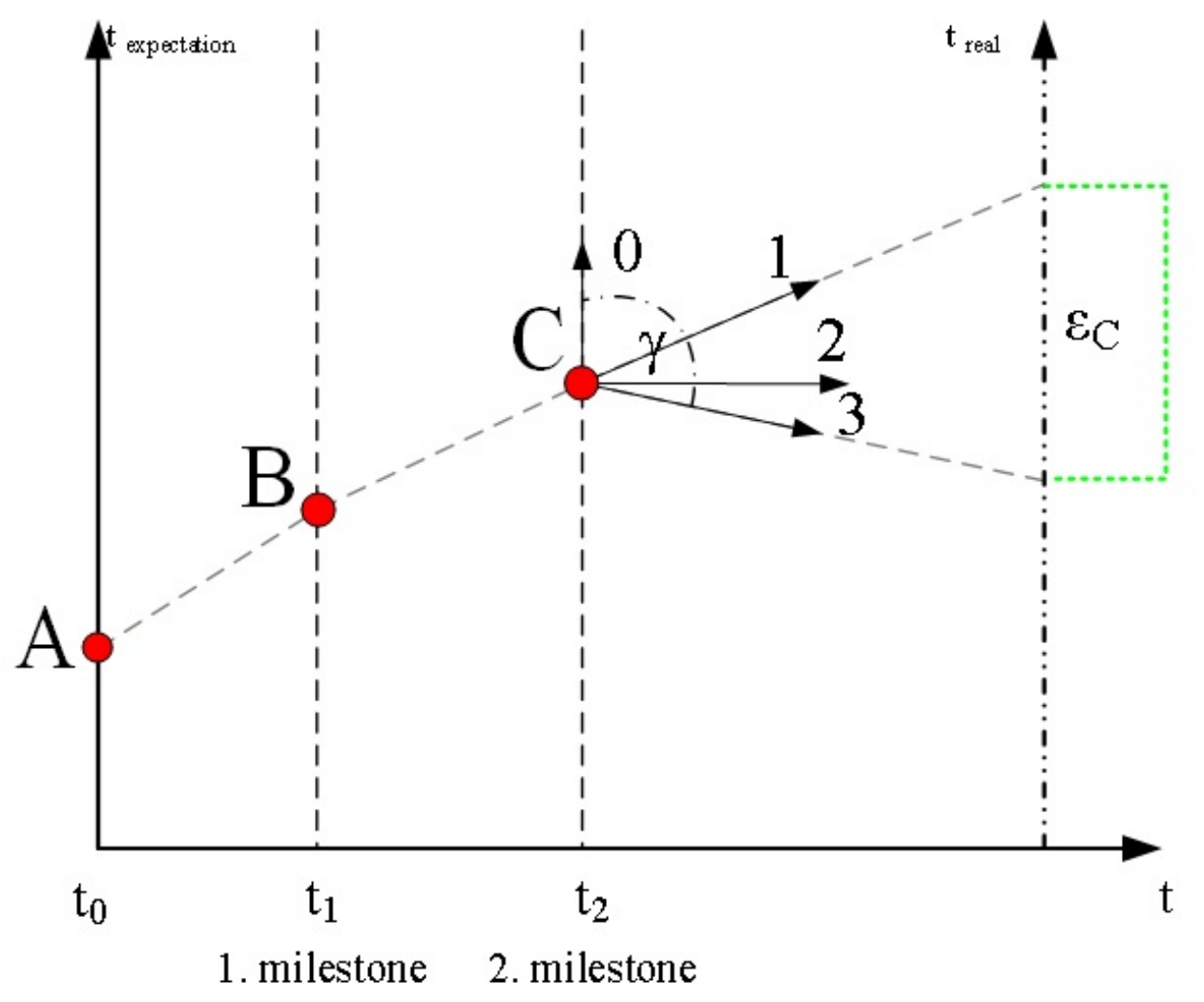

Figure 3: Logistics uncertainty at second milestone.

this, we have developed an information management model that, under certain conditions in the field of logistics, can provide a numerical forecast and, over time, a steady decrease in logistics uncertainty. A formal description of the model is given.

We hope that this study can be a good starting point for developing a unified methodology that will later evolve into the logistic control system used in everyday practice and, if properly applied, will reduce the entropy that is inherent in logistics processes.

\section{AUTHOR CONTRIBUTIONS}

All authors contributed equally to this work. All authors have read and agreed to the published version of the manuscript.

\section{CONFLICT OF INTEREST}

We declare that there is no conflict of whatsoever involved in publishing this research.

\section{REFERENCES}

1. Spearman ML, Woodruff DL, Hopp WJ. CONWIP: Pull alternative to kanban. International Journal of Production Re- search. 1990;28:879-894. Available from: https://doi.org/10. 1080/00207549008942761.

2. Mallik S. Customer Service in Supply Chain Management. In: Hossein Bidgoil. The Handbook of Technology Management. Supply Chain Management, Marketing and Advertising, and Global Management. 2010;2:104.

3. Rajnai Z, Puskás B. The risks of network complexity, Bolyai Szemle, 23/2. 2014;p. 60-66.

4. O'Reilly CA. Variations in Decision Makers' Use of Information Sources: The Impact of Quality and Accessibility of Information. The Academy of Management Journal. 1982;25(4):756771. Available from: https://doi.org/10.2307/256097.

5. O'Reilly CA. Variations in Decision Makers' Use of Information Sources: The Impact of Quality and Accessibility of Information. The Academy of Management Journal. 1982;25(4):756771. Available from: https://doi.org/10.2307/256097.

6. Hartványi T, Bakó A. Transportation network realization with an optimization method, In proceedings of 4th International Symposium on Computational Intelligence and Intelligent Informatics, Luxor, Egypt. 2009;

7. Péter L. Ellátási lánc információs rendszerének architektúrája. MEB 2009 - 7th International Conference on Management, Budapest, Hungary. 2009;

8. Shannon CE. A Mathematical Theory of Communication. Bell System Technical Journal. 1948;27:379-423, 623-656. Available from: https://doi.org/10.1002/j.1538-7305.1948.tb00917.x. 


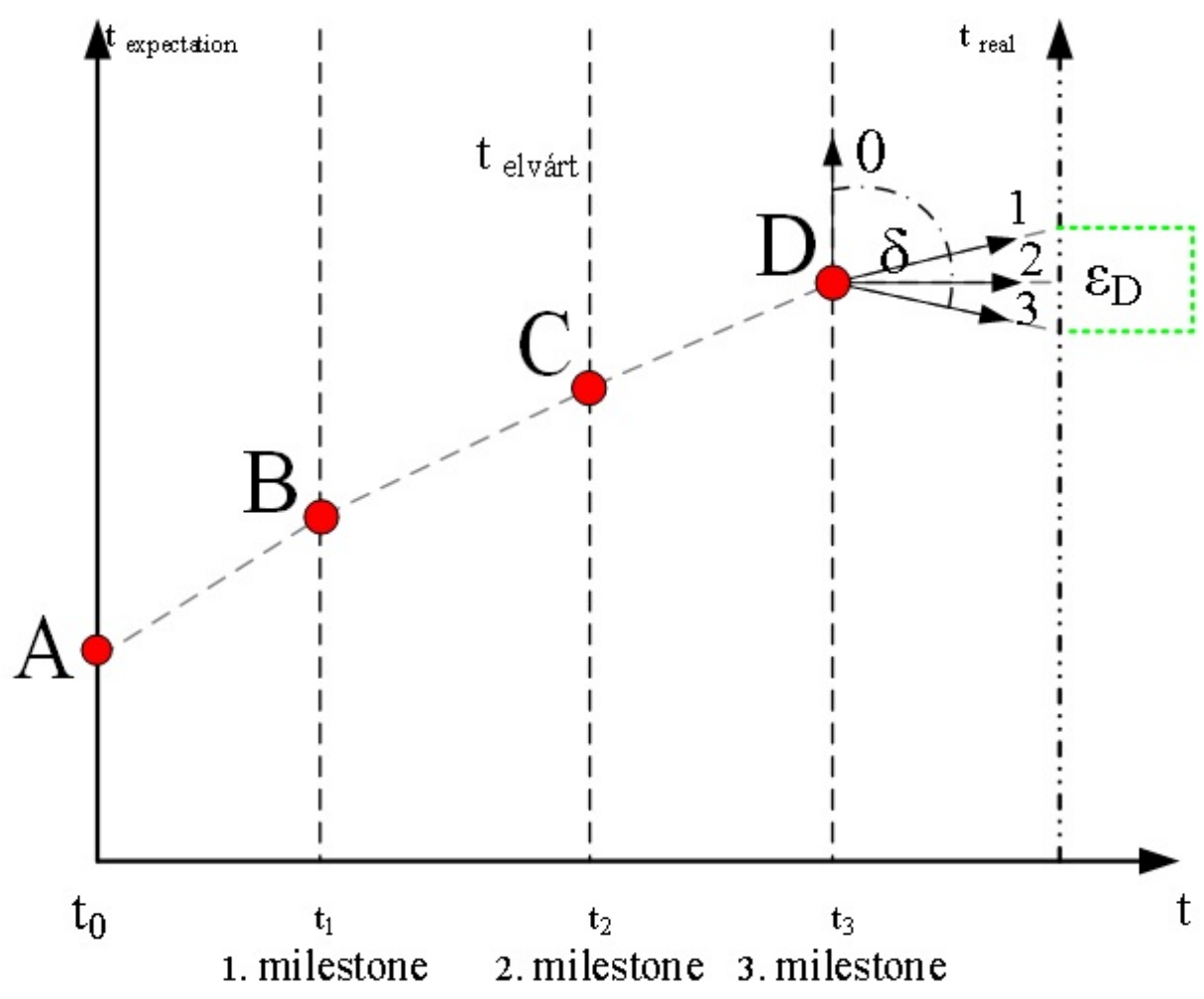

Figure 4: Logistics uncertainty at third milestone. 


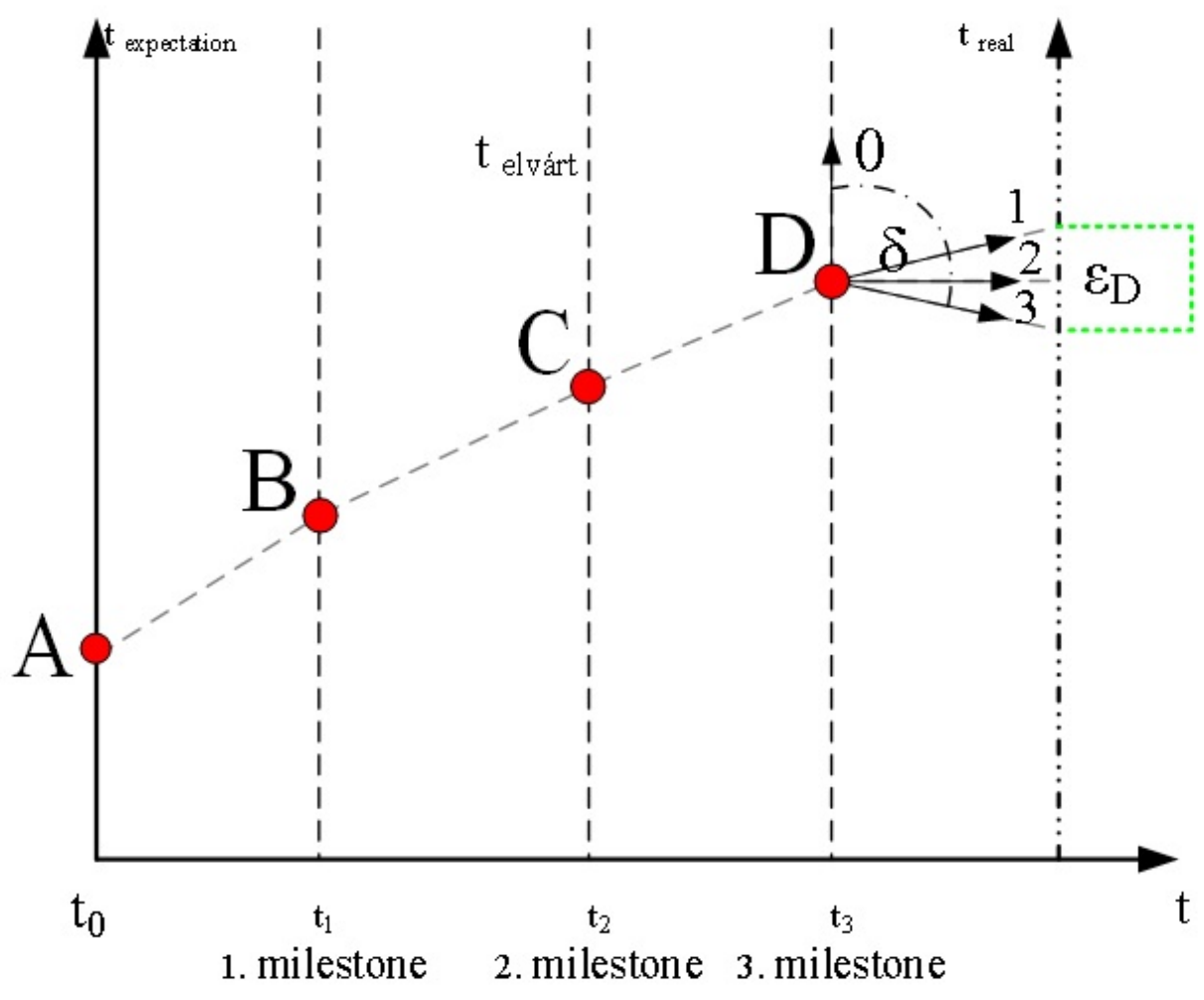

Figure 5: Theoretical diagram of possible outcomes. 